\title{
Modeling the effects of rainfall on vehicular traffic
}

\author{
Etikaf Hussain $^{1}$ (1) Syed Imran Ahmed ${ }^{1} \cdot$ Mir Shabbar Ali $^{2}$
}

Received: 8 September 2017/Revised: 31 December 2017/ Accepted: 2 January 2018/Published online: 15 January 2018

(C) The Author(s) 2018. This article is an open access publication

\begin{abstract}
Traffic management and drainage system are two vital issues for any metropolitan city. Like other big cities, Karachi is also facing problems due to lack of traffic management and poor drainage system. The main objective of the study is to model the interdisciplinary issues of storm water and its effect on the traffic of Karachi. The specific objectives are: (1) to calibrate and validate urban hydraulic and traffic micro-simulation models and (2) to model storm water and traffic for future conditions. This study is carried out on a $3-\mathrm{km}$ section of arterial road. In this study, loose coupling of two models is done. For urban drainage, PCSWMM, and for traffic, VISSIM is used. Both models are calibrated for an existing situation on rainfall event of August 3, 2013, and then used for prediction of future scenario based on 50-year and 100-year return periods of rainfall. Sensitivity analysis of VISSIM is performed. Locations and lengths of road sections, where ponding happens for the future scenario, are identified using PCSWMM. These lengths are then marked in VISSIM as low-speed areas, and delays are measured. Analysis of PCSWMM shows that for 100 -year return period, there is maximum 0.318 ha-m (3180 cubic meters) water stored in the depressions of the road after $10 \mathrm{~h}$ of rainfall. Analysis of VISSIM shows that for a 100-year return period, there is a maximum delay of $35 \mathrm{~min}$ on NIPA to Hasan Square section of University Road.
\end{abstract}

Etikaf Hussain

e.hussain@qut.edu.au

1 Civil Engineering Department, NED University of Engineering \& Technology, Karachi, Pakistan

2 Faculty of Civil Engineering and Architecture, NED University of Engineering \& Technology, Karachi, Pakistan
Keywords Traffic micro-simulation .

Hydraulic modeling · Rainfall · Delays · Ponding

\section{Introduction}

Karachi is considered to be the economic hub of Pakistan and contributes a large share in the gross domestic product (GDP) due to her favorable location at the Arabian coast. Road network is the skeleton for any city. The performance of the road network determines the capability and capacity development of the city. Pakistan, especially Karachi, has recently been facing difficulties in the road performance [1]. There exist various reasons such as increasing population, perennial movement of vehicles, poor road structure. However, for urbanized cities, there is another factor responsible for the poor performance of the impervious land which is intensified by poor drainage system in the case of Karachi. This impervious land is responsible for flooding within the city. Whenever there is a rainfall event, more specifically during monsoon in Karachi, ponding on the roads is usual. Ponding on the roads creates a lot of problems because it disturbs the flow of vehicles. After rain, it is very prominent to see congestion on the arterial and sub-arterials of Karachi city.

During rain, drivers tend not to accelerate high, keep low speed, and drive more cautiously. It is because acceleration and speed are directly involved in the capacity of the road section. So, due to rain, when the capacity of road decreases, it results in the long queue. Furthermore, due to the bad drainage system of the city, water tends to accumulate at the depression areas and inundation occurs. Generally, this inundated water completely blocks the road, resulting in almost zero capacity of that section of the road. This causes an increase in travel time and a decrease in 
road capacity. This inundation sometimes remains for days, if ponded water is not drained by some external means like pump.

Drainage and traffic management are always two important issues of an urban area. Karachi is also facing severe difficulty in dealing with management of drainage and traffic. Substantially, when these two issues are studied together, the scenario becomes more catastrophic, based on complications of each field. Due to poor management of drainage and traffic, a rainfall event becomes a tragedy. This often occurs when there is a poor planning of the region. This issue needs to be addressed accordingly, especially in the urban environment, since urbanized areas have to be the pivotal focus of planning development and management as mentioned in various studies [2,3].

To overcome the above-mentioned public-related issues, it is of great value if a research study based on some observed data could be conducted to give recommendations for improvement of the current situation of traffic. In addition, it is needed to improve the existing drainage system to ease the traffic congestion in rainy conditions. These issues can be in designing, planning, and management of the drainage system. By thorough analysis of observed data, these issues can be addressed effectively.

History dates back to the situation when precipitation was $205 \mathrm{~mm}$ annually, which has decreased by $14 \mathrm{~mm}$ since then [4]. During those years, the land was less impervious as compared to the existing land use. Even though rainfall has decreased, there is more flooding being observed. This is due to the increase in impervious land due to urbanization. Consequently, flooding affects the ongoing traffic. To emphasis more, the modes of transportation in previous years were usually trams, buses, carts, etc., which have now changed to automobiles, vans, and motorcycles. The increase in vehicles increases traffic disturbing situations at rainfall events.

The main objective of this research study is to model the interdisciplinary issues of storm water and its effect on the traffic of Karachi. The specific objectives are (1) to study the observed traffic and storm water data to identify the traffic issues, (2) to calibrate and validate urban hydraulic and traffic micro-simulation models, and (3) to model storm water and traffic for future conditions.

\subsection{Study area}

The study area selected is a section of an arterial road, University Road, Karachi, Pakistan. This road has high volume peak in the morning (7:30 am to 9:00 am) on both ways because this road connects the city business district (CBD) and educational institutes to residential areas. Length under study is a road stretch of $3 \mathrm{~km}$ from Hasan Square (Civic Center) to National Institute of Public
Administration (NIPA). It is a six-lane, two-way road separated by $10 \mathrm{in}$. high and $5 \mathrm{ft}$ wide median, having trees on the median. This section of the road widens to more than three lanes at some places; however, as an average, there are three lanes in one direction having approximate width of $3.5 \mathrm{~m}$ per lane. The fence is provided on most of the running length of median. For pedestrian crossing, three pedestrian bridges are provided at different intervals. Figure 1 shows the area of the University Road under study.

At $15 \mathrm{~m}$ from NIPA, there is a flyover having a length of $740 \mathrm{~m}$ over the existing Karachi Circular Railway (KCR) track. While traveling from NIPA to Civic Center, there are three left turns, whereas in the opposite direction, there are six left turns. Within this section of road, there is one U-turn. There is no defined bus stop. Boarding and alighting happen at rudimentary arrangements. Furthermore, the analysis of this section shows that there is no issue of encroachment. The road coming to NIPA from Civic Center has service lane as well, contrary to the other way of the road.

The digital elevation model (DEM) of the study area shows that this section of the road has a relatively flat terrain with a maximum drop in elevation not more than $5 \mathrm{~m}$ over the $3 \mathrm{~km}$ distance. In the north of this road, there is Lyari River that serves as an outlet for the area under study. All wastewater and storm water of study area are dumped into this river which gets released to the Arabian Sea.

In order to study the effect of rainfall on traffic, the trend and occurrence of rainfall are a prerequisite. United States Environmental Protection Agency (USEPA) report states that since 1901 global precipitation has increased at an average rate of $1.9 \%$ per century [5]. The variation in the trend and periodicity of rainfall can be local. A study shows that the annual precipitation of Karachi city has decreased $36 \mathrm{~mm}$ in the last 51 years (1961-2012) [6]. Based on these studies, there is a need of evaluation of traffic-rainfall effects in future for proposing better planning and management techniques.

\subsection{Effect of rainfall on traffic}

Considerable work has already been done on the effect of inclement weather on traffic. Majorly, the research has been carried out in developed countries [7], which showed the weather impact on the flow characteristics and capacity on urban freeways. Results of this study showed that for rainy conditions of trace, light, and heavy, the average reduction in capacity was $1 \%-3 \%, 5 \%-10 \%$, and $10 \%-$ $17 \%$, respectively. Results of this study were found as compliant with the results provided by Highway Capacity Manual (HCM). Another study [8] showed the higher 


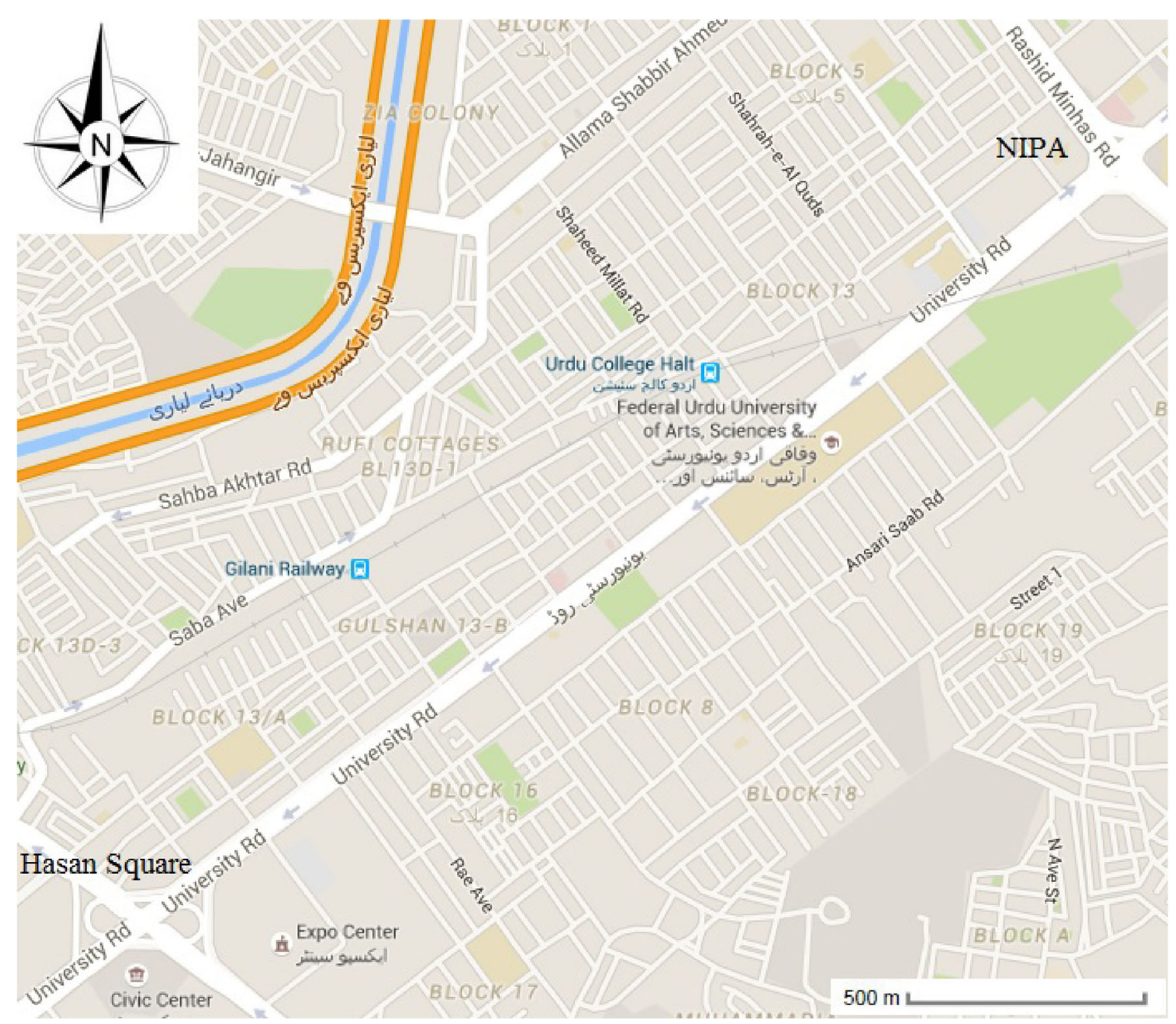

Fig. 1 Map of the study area (Courtesy: Google map)

values $(25 \%)$ for a reduction in capacity for rainy condition.

Similar to the research work mentioned above, scientists have modeled various scenarios to highlight the effects and provided solutions to minimize the disturbance. In one study [9], the analysis of bad weather on the hourly traffic volume was done for Buffalo, New York, USA. The conclusion of the entailed that effect became more significant during peak hours as the percentage reduction in volume reached up to $34 \%$. Furthermore, study also showed that wind speed and temperature had the least impact on traffic while visibility had the highest influence on hourly traffic volume.

Feng et al. [10] developed a regression equation in which they incorporated various factors such as lane factors as spatial factors and temporal factors, i.e., month, day, and time of traffic operation, which affect the operating speed and road capacity. It was concluded that rain had a negative impact on the operating speed and road capacity.
In addition, rain had greater influence as compared to all other factors which tend to decrease the traffic.

Researchers have also evaluated the effect of weather on free-flow speed. This study emphasizes on a rural interstate highway road in Idaho, Moscow, USA [11]. This study incorporated many variables like road condition, wind speed, and visibility. The results showed that there was a considerable decrease in speed in inclement weather condition where visibility was the strongest factor affecting the speed. This was concluded to be related to rain with high intensity and/or when there was snow, and the visibility became too low. A study in Korea [12] on freeway system showed that there was a delay of 1.8 million vehicle-hours per year due to non-reoccurring congestion because of rain. Further analysis showed that the delay per unit distance was dependent on rainfall duration and intensity. The suggestion of the study is to offer speed management during rain, i.e., reduction in the speed of vehicles during rain must be minimized. In other studies 
$[13,14]$, it is shown that there was a considerable amount of reduction in the speed of vehicles when the pavement surface was wet. The studies suggested that the places where poor weather condition prevailed for the most time of the year, the effect of weather in designing of a road facility should be kept as priority. The cited literature for the effect of inclement weather on traffic suggests that rain can cause reduction in overall capacity of roads, which results in longer delays and queuing. All of the above-cited work is about the weather or rainfall effect on the traffic. These studies have carried out in countries other than Pakistan. However, more work is being carried out in Pakistan regarding urban hydrology. Also, these studies do not incorporate integration of hydraulic and traffic modeling for the prediction of future scenarios.

In recent years, computer-based modeling approach has become an effective tool for water resource and traffic management. Various models are used for the simulation of urban hydrology and hydraulics. These models perform various functions and analyze the parameters at ease which once used to be a hard job at hand. Some of the hydrology and hydraulic models such as Hydrologic Engineering Center-River Analysis System (HEC-RAS) [15], Hydrological Simulation Program-FORTRAN (HSPF) [16], Soil and Water Assessment Tool (SWAT) are capable of simulating the watershed in detail, giving outstanding results. Moreover, there are traffic models that perform analysis based on various traffic parameters. Some of the models are 'Verkehr In Städten-SIMulations modell' (German for 'Traffic in cities-simulation model') (VISSIM) [17], CORridor SIMulation (CORSIM) [18], SimTraffic [19], Advanced Interactive Microscopic Simulator for Urban and Non-Urban Networks (AIMSUN) [20], Quadstone Paramics [21], etc.

With more impervious land, the increased occurrence of flash floods becomes evident. A study [22] done for Dhaka city, Bangladesh, highlighted how urban flooding could be simulated by one-dimensional hydrodynamic model by integrating the buried drains, assuming roads as open channel flow and stagnant water ponds. Conclusions elucidated that such modeling could be used for design and management of urban drains that are faced by flooding. A case study analysis of the University of Memphis, USA, developed and tested a GIS-based urban flood inundation model. The model had two parts: storm runoff model, and an inundation model. Cumulative surface runoff, which was an output of the storm-runoff model, served as input to the inundation model. The adapted flat water model was found to be a useful alternative to a physical-based dynamic model considering computation requirements. It is recommended to be useful for urban planning and emergency preparation because of its time-efficient performance and low requirements to input and hardware [23].
Hydrologic and hydraulic modeling performance determines how effective the models are to study various factors for urban areas as well. An urban inundation model, combining a storm sewer model SWMM, two-dimensional (2D) diffusive overland-flow model and operations of pumping stations, has been developed in a study [24] for Taipei City, Taiwan, China, to simulate inundation in urban areas caused by the surcharge of storm sewers and outlet pumping stations. The simulation results suggested that the authority may prevent flood damages by redesigning and enlarging the capacities of storm sewer systems or the pumping stations in the inundation-prone areas.

In one study [25] PCSWMM was used to investigate the change in surface flooding due to possible climate change. The area under study is Rattanakosin Village, Thailand. This area is on the outskirts of Bangkok. The year 2000 is selected as base year. Results of the study showed that the flooding at nodes was increased by approximately 1.3 times from the year 2021 to 2091 .

Urban area flooding due to lack of adequate sewer system is an important issue. In Europe, it has been an important issue since it causes loss of millions of dollars against potential damage to buildings and other structures. The dual drainage model, RisUrism [26], has been developed in order to meet the necessities of simulating urban flooding. The model was applied to a sub-catchment in the city of Kaiserslautern, Germany. The research suggested a permanent link between hydraulic surface flow and sewer flow in the flow routing procedures in order to more accurately assess water levels to avoid possible damages due to flooding.

Model, namely VISSIM, is capable of incorporating rainfall effect on traffic. Hou et al. [27] provided guidelines for the traffic flow model calibration and the parameters needed to study under poor weather conditions like snow and rain. The study indicated that traffic was reduced by $30 \%-40 \%$ in heavy snow. The authors suggested that the traffic parameters could be used as an input in the simulation software. For snowy conditions of Austria, VISSIM has been calibrated to identify the variables important for calibration and those which are sensitive to snow. The results showed satisfactory curves between observed and simulated traffic flows [28].

A similar study was carried out at West in Pasadena, California, USA, where detailed calibration was performed for a congested freeway using VISSIM. After defining geometric data and VISSIM coding, sensitivity analysis of driver behavior parameters is performed to find sensitive parameters for the calibration process [29].

As mentioned above, some of the traffic models, there is a study that has been done to compare models and their performances. VISSIM and CORSIM, two frequently used 
models, were set to run and deliver their respective results. There was a consistency observed in both the models, showed similarity [30]. Both are capable of modeling combination of streets and freeways, including signal control and other strategies. However, the difference lies in the logic applied for car following and gap acceptance technique. Another study has been carried out to entail the differences and similarities of the two models in detail. Predictions performed by both models did an exceptional job. The level of service (LOS) prediction results matched, whereas HCM predictions showed some differences [30].

VISSIM gains its popularity as many traffic researchers and academicians use its applications and functions for various studies. It has been mentioned that functionality and versatility of this software execute a graphical user interface beneficial for engineers without dedicated computer knowledge to set up microscopic traffic flow models [31]. More comparative study has been done on traffic models. In one of the studies three traffic models, namely CORSIM, SimTraffic, and AIMSUN, are compared. The comparison was done based on the hardware and software requirements, the ease of network coding, data requirements and availability of defaults, and performance and accuracy. Results showed that SimTraffic is the easiest model to use, CORSIM was found capable of solving complex networks, and performance of AIMSUN model was concluded to be very much acceptable with its traffic assignment working best in comparison with the other two [32]. From above literature, it is concluded that PCSWMM is well capable of handling water drainage issues related to urban areas. Therefore, for water modeling part, PCSWMM has been selected. For traffic modeling part, VISSIM has been selected, which is nowadays renowned in traffic modelers for performing micro-simulation.

\section{Materials and methods}

After careful review of the literature, our study starts with the selection of models for both hydraulic and traffic modeling. For a model to simulate, data collection is a prerequisite. Data have been mustered up for each of the model based on their input requirements. The calibration and validation of models were done using the available input parameters. Figure 2 illustrates the methodology of the study using flowchart.

DEMs are vector-based or raster-based. The DEM used for this study is of $30 \mathrm{~m}$ resolution. This means that in this resolution, one tile is $30 \mathrm{~m} \times 30 \mathrm{~m}$. Rainfall has been attained from Pakistan Meteorological Department (PMD) for August 3, 2013, for the city of Karachi. The rainfall gauging stations in Karachi are at Karachi International Airport and Masroor Air Base. For this study, the data observed at Karachi Airport are considered, since it is near (approx. $6 \mathrm{~km}$ ) to the study area. The rainfall on this day was noted as $103 \mathrm{~mm}$. Out of $103 \mathrm{~mm}$ of rainfall, $46 \mathrm{~mm}$ fell in first one hour. Temperature data that have been noted for this study are again obtained from PMD. The temperature at this day was $90^{\circ} \mathrm{F}$.

Land use is crudely divided into pervious and impervious. Road section is almost $100 \%$ impervious; however, the median is pervious (with some sections covered with concrete), and there is plantation at median. These data are helpful for hydraulic modeling. The data for drainage infrastructure have been observed at the site. These data include the identification of manholes, their location, and their geometry. Moreover, the information for silting and clogging of every manhole and drainage path was observed which is used for the calibration of hydraulic model.

The vehicle flow was observed by counting the vehicles from closed-circuit television (CCTV) videos. These videos also provide the data for vehicle composition in the traffic stream. GPS-mounted vehicle was used to note timebased speed of the vehicle. This vehicle was first moved from NIPA to Hasan Square and then on the other direction as well. The data attained from this vehicle were plotted on MS Excel to generate the speed distribution.

Traffic volume survey was conducted to get the actual number of vehicles taking left turn or right turn (U-turn) from the mainstream. There are three left turns, while traveling from NIPA to Hasan Square, whereas in an opposite direction there are seven left turns. There is one U-turn, approximately in the mid of under study road section. Right before the NIPA flyover, there is a diversion which takes traffic from University road to Gulshan roundabout.

After studying various models, PCSWMM has been chosen as the most suitable hydraulic model for this study. It is a computer-based program that has been developed by United States Environmental Protection Agency (USEPA). Further interface of the model was done by CHI [33]. Since its first development, it has undergone various versions. The version used for this study is the 13th version. PCSWMM is a model that simulates various components of hydrology and hydraulics such as runoff from rural and urban areas, rainfall interception in depression storage, percolation of infiltrated water into ground water layers [34]. It is very advanced in terms of working with GIS data and incorporates GIS engine for hydraulic modeling. The model is capable of illustrating results in one-dimensional (1D) and two-dimensional (2D).

For better visual and understanding, 2D modeling has been used for this study. PCSWMM 2D extends the fully dynamic $1 \mathrm{D}$ approach to 2D free surface flow. Based on the equations of continuity and conservation of momentum, this model entails the outputs. 


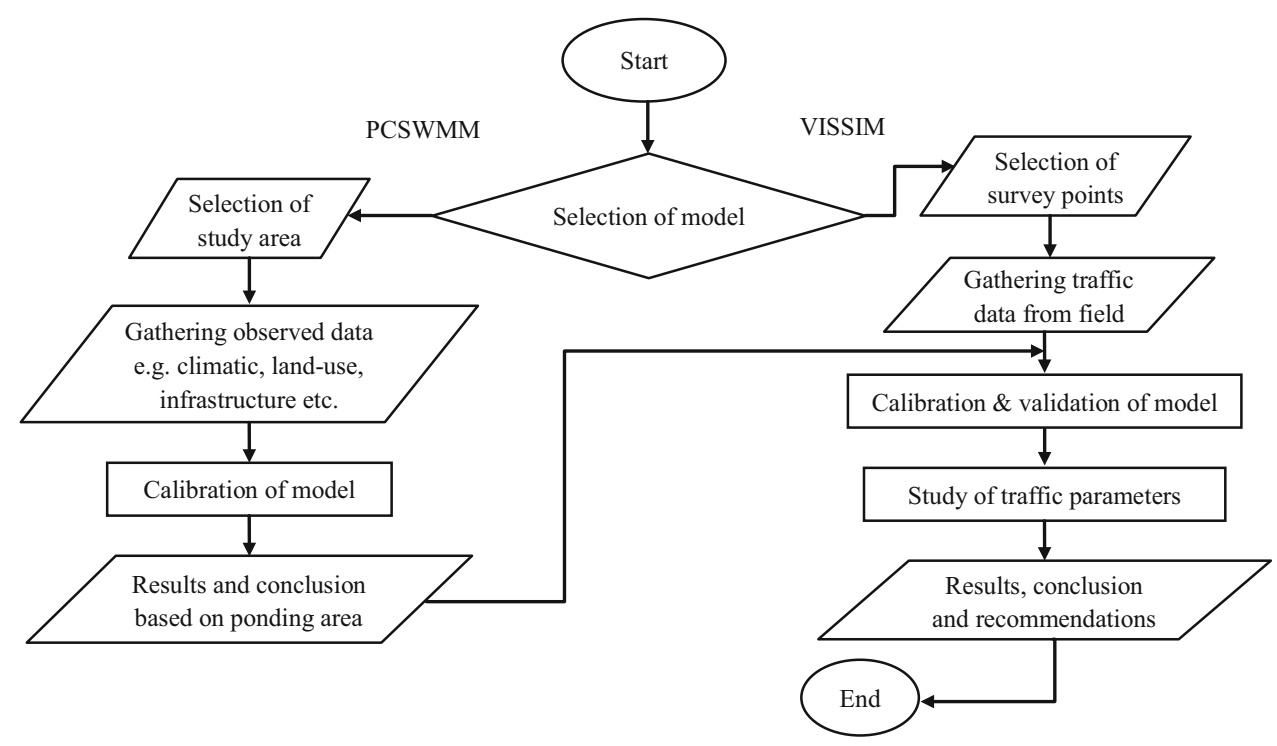

Fig. 2 Flowchart showing methodology of the study

2D domain is discretized by PCSWMM 2D, using square or hexagonal mesh, and represented it by $2 \mathrm{D}$ nodes. All nodes are connected to each other by rectangularshaped open channel, which are tagged as 2D conduits. 2D nodes are given surface area of $0.1 \mathrm{~m}^{2}$. PCSWMM does adjustment to length and width of those rectangular conduits depending upon the link coming in or out of the node. PCSWMM can calculate the water velocity on an averaged depth for each 2D cell.

In this study, two models PCSWMM and VISSIM are loosely coupled. Loose coupling is a renowned and widely used term in computer simulation modeling. It means that the output from PCSWMM (ponding depth, its area, and duration associated with a particular rainfall) as shown in Fig. 2 is used as input in VISSIM as the low-speed operating areas.

\subsection{Water modeling: PCSWMM}

PCSWMM has been taken into consideration for simulation of rainfall on the urban area. Provided the input data, this model goes through the following steps. GIS-based layers are imported to the model, selection of 2D modeling tab, generation of new data files, input of meteorological data, creation of drainage infrastructure, and running of simulation.

For this study DEM and aerial image layers are imported which are the minimum required data layers. DEM of $30 \mathrm{~m}$ is imported for the elevation dataset and topography. In addition to PCSWMM, ArcGIS and Global mapper are used for conditioning of the DEM.

Three layers, namely bounding layer, 2D nodes layer, and DEM layer, are compulsory to provide in order to run
PCSWMM in 2D mode. In this study, bounding and obstruction layers are provided. Bounding layer defines the boundary of area of interest, and obstruction layer is provided to locate the places where water cannot travel or the places which have less width and higher elevation. Bounding layer defines the working boundary, and 2D node acts like a junction having surface area of $0.1 \mathrm{~m}^{2}$ as directed in PCSWMM manual. The last required layer is mesh layer. Mesh layer contains the rectangular conduits having variables, lengths, and widths depending upon the number of conduits getting into or out of the node. The conduit starts from one 2D node and ends at an another 2D node.

Meteorological data required by PCSWMM are daily temperature and rainfall. Calibration is performed for the rainfall event of August 3, 2013; therefore, the temperature and rainfall data on the above said date are input. For the said date, during $24 \mathrm{~h}, 103 \mathrm{~mm}$ of rainfall is recorded in which $46 \mathrm{~mm}$ of rainfall occurred in first hour from 11:00 am to $12: 00 \mathrm{pm}$. Rest of the $57 \mathrm{~mm}$ is after 12:00 pm to 8 a.m. The simulation is performed for the peak hour; therefore, only $46 \mathrm{~mm}$ is input as baseline flow into each junction.

The next step in PCSWMM simulation is to provide the drainage infrastructure. On that rainfall event day, a site visit was made and observations were taken from the site. The manholes contributing in taking storm water out were considered and analyzed. Once all the inputs are ready, simulation is done for the existing condition. Approximately, $105,000 \mathrm{~m}^{2}$ (10.5 ha) area is modeled. The number of $2 \mathrm{D}$ junctions modeled is 1439 , and number of conduits is 3019. The model is run for the dataset, and it takes around 5 min for the model to simulate at every junction and 
conduit. The output is observed as a graphical flood depth pattern.

PCSWMM is calibrated using the ponded depth values of area under study during and after rainfall event. The boundary conditions of outlets are also changed to get the required results. During the study period, one rainfall event occurred and was used for calibration of the model.

\subsection{Traffic micro-simulation modeling: VISSIM}

Selection of traffic model, 'Verkehr In Städten-SIMulations modell' (German for 'Traffic in cities-simulation model') (VISSIM), is developed by Planung Transport Verkehr (PTV) (1992), Germany. This is a computer-based micro-simulation program that performs time step and behavior-based simulation for public transport operations and flows of pedestrians. For this study VISSIM 5.90 is used. The model performance depends on the number of signal control junctions, number of vehicles, or pedestrians contained in the network. The output of VISSIM is displayed as real-time scenario.

VISSIM has been taken into consideration for microsimulation of traffic on the selected stretch of University Road. Provided the data, this model undergoes the following steps: importing satellite imagery and creation of links, providing base data, adding vehicle composition, input of traffic data, setup for analysis, and simulation of the model.

To draw the road network, it is essential to first import either satellite imagery or an AutoCad-generated file that has layout of complete network (road section). VISSIM has its own tool to draw links or section of the roads. For this study, the type of road is used as urban motorized road, the number of lanes in each direction is entered as 3, and lane width is taken as $3.5 \mathrm{~m}(11.5 \mathrm{ft})$.

From CCTV videos, the type of vehicle is obtained. The traffic stream consists of cars, motorcycles, buses, trucks, rickshaws, Qing-Qi (six-seater tricycle), and small-sized pickup trucks. For simplicity of the model, trucks and small trucks are kept under the same category. Also, rickshaw, Qing-Qi, and motorcycles are kept in one group that is motorcycles.

Setting driving behavior parameters are important as they play a vital role in calibration. VISSIM uses either Wiedemann psychophysical car following model of 74 or 99 or vehicles with no interaction [35-37].

Traffic data are required for micro-simulation of traffic. Traffic volume at 15-minute interval is extracted from videos provided by Citizens-Police Liaison Committee (CPLC), Karachi. Vehicle composition is required by VISSIM to introduce exact percentage into the traffic stream as they are in actual traffic stream. Percentages of vehicles are also quantified from videos for every 15-minute interval. The distribution of vehicles such as car, motorcycle, truck, and bus was $41 \%, 32 \%, 7 \%$, and $2 \%$, respectively.

Next step in modeling traffic in VISSIM is to provide volume of traffic on the road. Traffic data are broken into 15-minute interval. At first, $900 \mathrm{~s}$ are given an appropriate volume as warm-up for the model, and after $900 \mathrm{~s}$, actual data are input in model.

For calibration, the observed volume per hour was compared with the simulated volume per hour. Commonly, the equation used for the calibration of micro-simulation model is Geoffrey E. Havers (GEH) statistics [37]. It is a goodness of fit test and also called modified Chi-squared test. GEH statistics is calculated by:

$\mathrm{GEH}=\sqrt{\frac{2(M-C)^{2}}{(M+C)}}$,

where $M$ is the simulated hourly traffic volume (in vehicles) and $C$ is the observed hourly traffic volume (in vehicles).

After calibration of the model, validation was performed, which confirms the satisfactory simulation of the model. Validation shows that the model is ready for further applications. Since calibration is performed for one direction of the study area (that is the road from Hasan Square to NIPA), validation is performed for the other direction, which is from NIPA to Hasan Square.

\subsection{Sensitivity analysis}

Sensitivity analysis is only performed for the VISSIM parameters. Wiedemann's 99 parameters have been chosen to work with instead of Wiedemann's 74 parameters because this gives more control over the driving behavior parameters. All ten driver behavior parameters (from $\mathrm{CC} 0$ to $\mathrm{CC} 1$ ) and two lane-changing parameters have been included in the analysis. For sensitivity analysis, each parameter value is changed at once, while other parameters remain at default value. Each parameter values tested are taken $\pm 10 \%, \pm 20 \%, \pm 30 \%, \pm 40 \%$, and $\pm 50 \%$ to its default value except for lane change parameters. For lane change the default values are $1 \mathrm{~m}$, and this is the maximum value the software accepts for this parameter. Therefore, $0.5 \mathrm{~m}$ is taken as standard value and the other values taken for analysis are $\pm 0.1, \pm 0.2, \pm 0.3, \pm 0.4$, and $\pm 0.5 \mathrm{~m}$.

The results of various scenarios are shown in Fig. 3. It is concluded that headway parameters $(\mathrm{CC} 0, \mathrm{CC} 1$, and $\mathrm{CC} 2)$ have more influence on the road capacity, while the lane- 
changing parameters are found to be most sensitive parameters as shown in Fig. 3j, k.

\subsection{Future scenario}

After the simulation and validation of the models, PCSWMM and VISSIM, the models have been run for future scenarios. Based on 50-year and 100-year return period of rainfall, PCSWMM has been run to generate the future flood depth and area of inundation. The amount of rainfall for 50- and 100-year return period is $2.6 \mathrm{in}$. $(66 \mathrm{~mm})$ and $3.2 \mathrm{in} .(81 \mathrm{~mm})$ for duration of one hour. The results of PCSWMM are then used in VISSIM to incorporate the effect of rainfall on traffic. Also, in VISSIM, for peak scenarios, peak hour volume for both directions has (a)

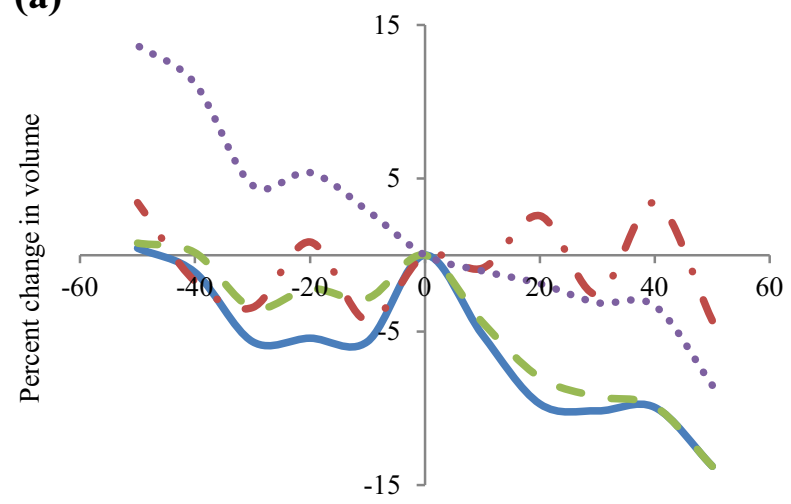

Percent change in default value

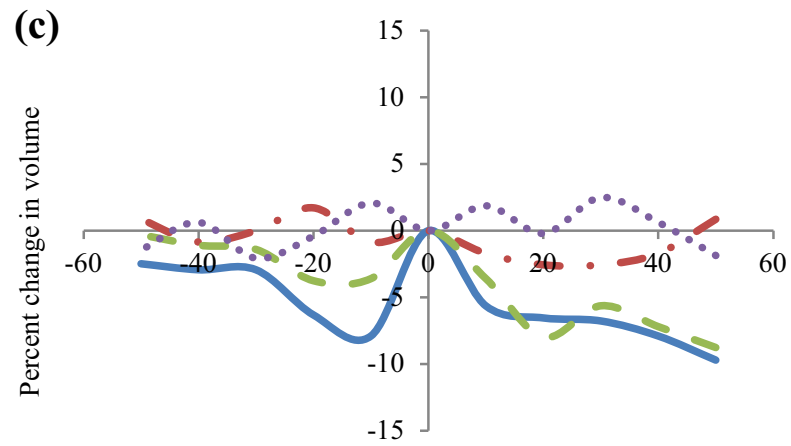

Percent change in default value

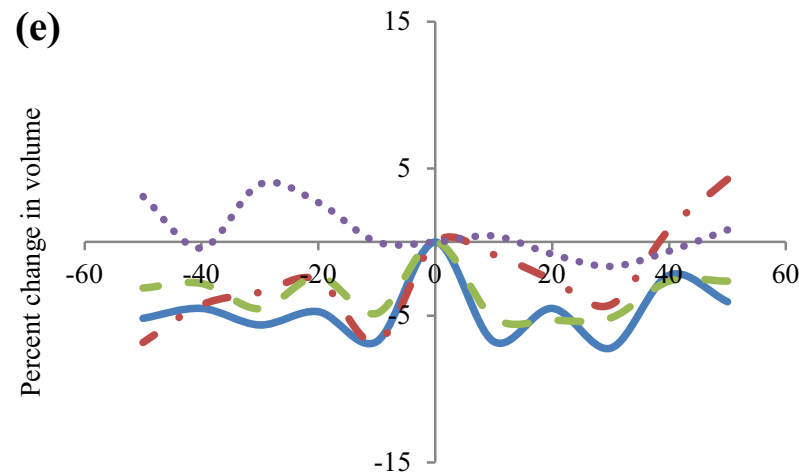

Percent change in default value

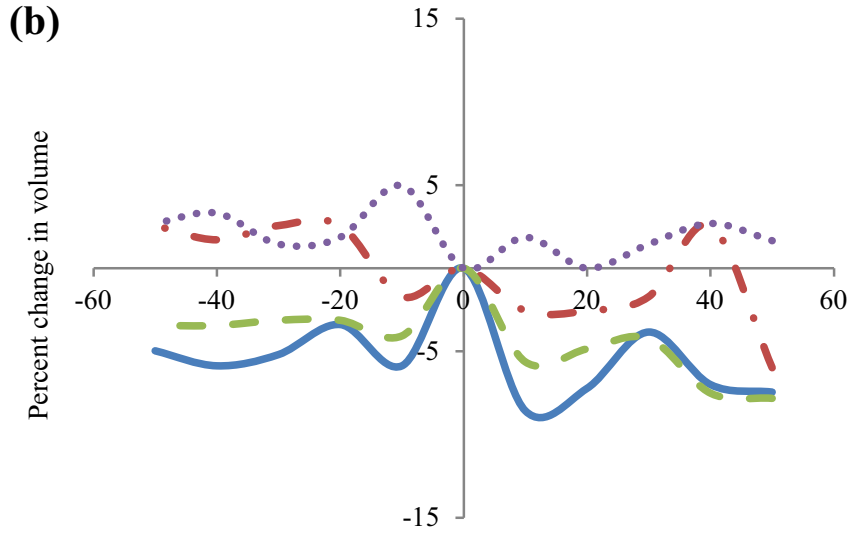

Percent change in default value

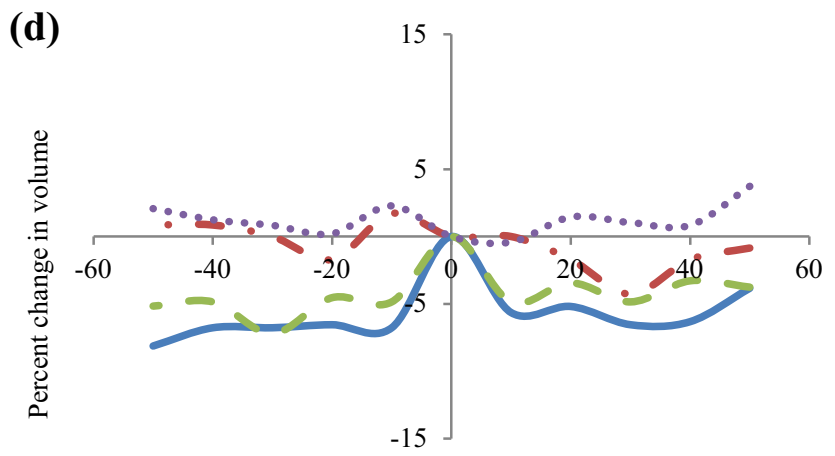

Percent change in default value

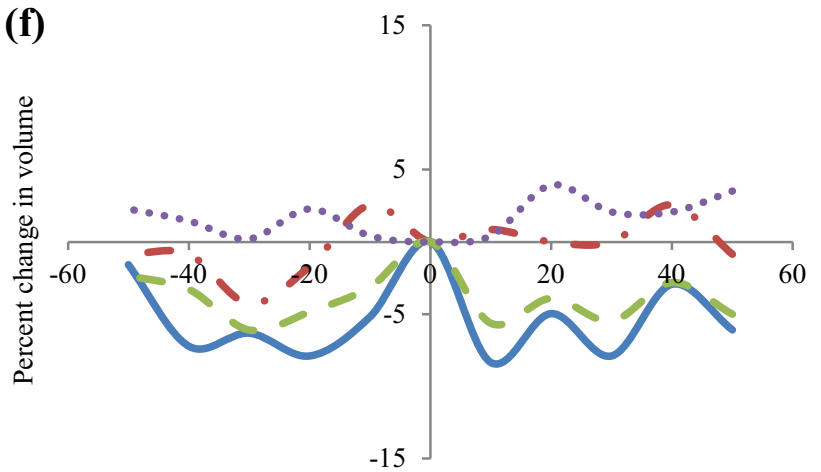

Percent change in default value

Fig. 3 Sensitivity analysis results for different scenarios. Standstill distance CC0 (a), headway time; CC1 (b), 'following' variation CC2 (c), threshold for entering 'following' CC3 (d), 'following' thresholds CC4 an CC5 (e), speed dependency of oscillation CC6 (f), oscillation acceleration CC7 $(\mathbf{g})$, standstill acceleration CC8 (h), acceleration at $80 \mathrm{~km} / \mathrm{h} \mathrm{CC} 9(\mathbf{i})$, lateral distance at $0 \mathrm{~km} / \mathrm{h}(\mathbf{j})$, lateral distance at 0 and $50 \mathrm{~km} / \mathrm{h}(\mathbf{k})$ 


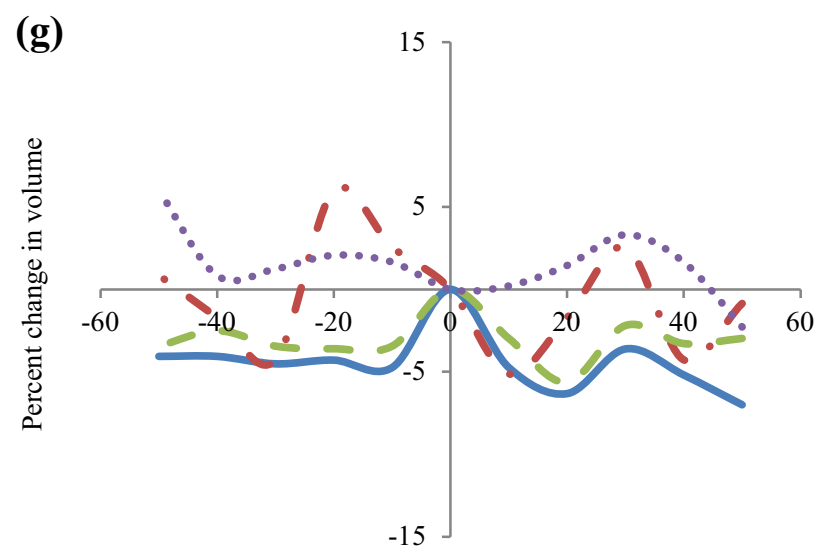

Percent change in default value

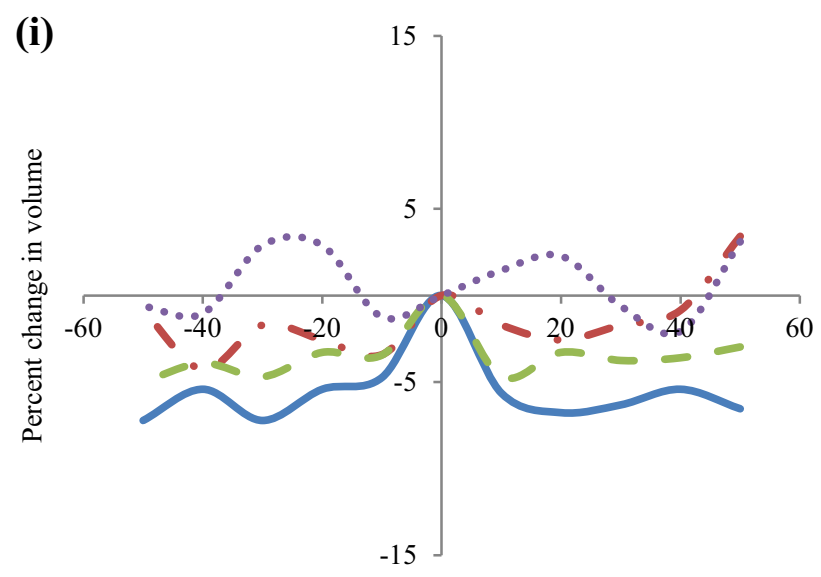

Percent change in default value

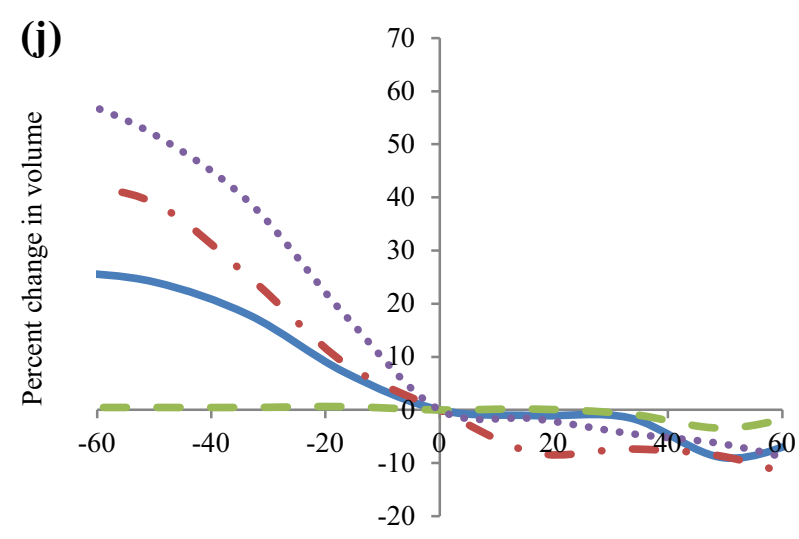

Percent change in default value

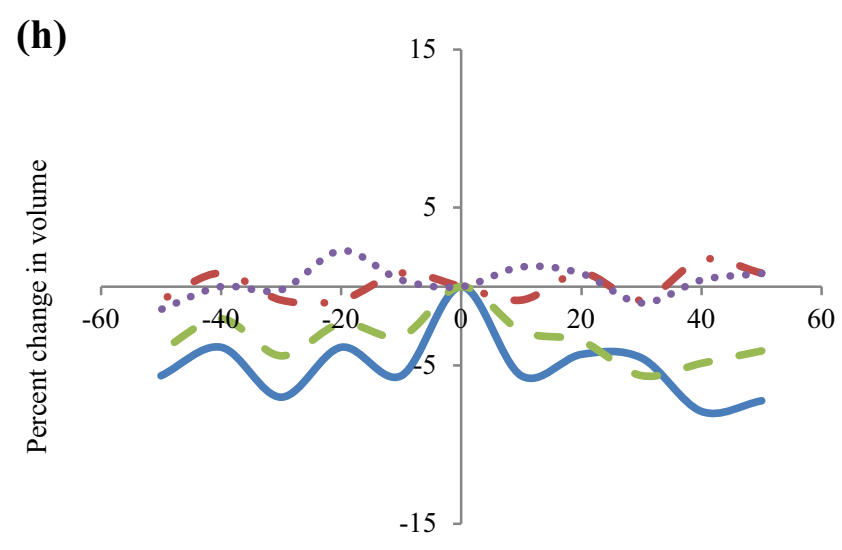

Percent change in default value

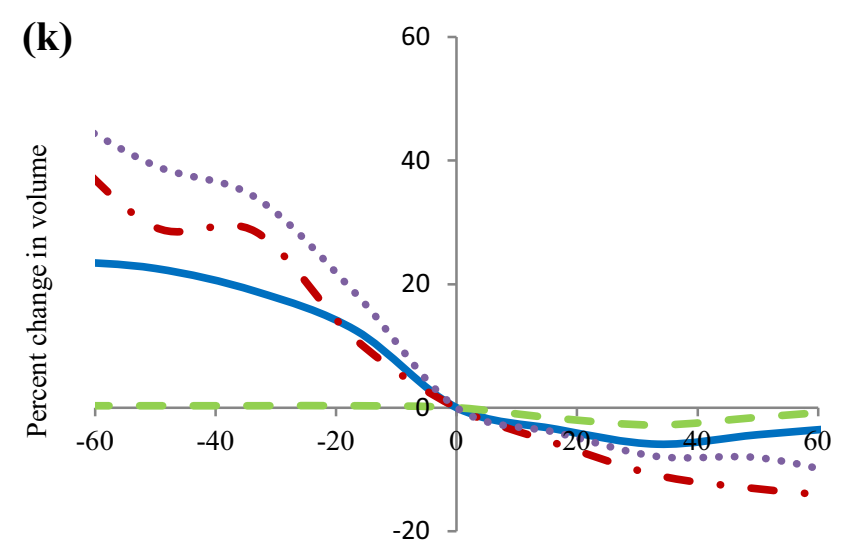

Percent change in default value

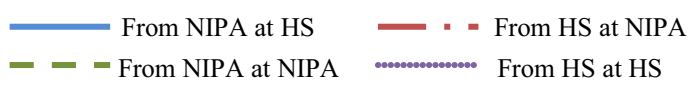

Fig. 3 continued 
been used. From VISSIM, traffic volume for selected rainfall event, queue length, and delay time is processed.

\subsection{Analysis of PCSWMM}

PCSWMM was used to simulate the rainfall situation for the study area. Using input data PCSWMM was first calibrated. Calibration required adjustment of boundary conditions at outfall or the condition at manhole, if it is clogged or not, and attainting their most suitable value that fits in the real-time situation. Table 1 illustrates the calibration results of PCSWMM for the observed and simulated ponded depths. If the model input parameters such as the rainfall amount, size of manholes, size of pipes, percent of pipe clogged, roughness coefficient for land and pipes are chosen according to the model functions, the observed and simulated values should not vary too much. For calibration, the input variables are changed manually to match the simulated depths with the observed depths. Table 1 also shows the percentage error for various locations between the observed and simulated depths.

For three sets of location, as mentioned according to their coordinates, the depths are simulated in PCSWMM. The model has shown fairly good results. Models that show routing error less than $1.0 \%$ are considered as good models. Model with routing error more than $1.0 \%-5 \%$ needs some investigation, while routing error above $5 \%$ needs some thorough checking of the model [38]. The model has a routing error of $0.435 \%$, which is in the acceptable range. The model has been run for $10 \mathrm{~h}$ of time period. The modeling results show that at the end of simulation there is final stored volume of 0.301 ha-m $\left(3.012 \times 10^{6} \mathrm{~L}\right)$ which implies 0.301 ha-m of water stored on the surface of the road. The reasons for this volume might be poor drainage and/or depression in the roads. The ponded water will remain there on the surface until and unless not removed by some external source like pump.

\subsection{Calibration of VISSIM}

VISSIM based model is run for the rainfall event of August 3, 2013. VISSIM is calibrated using the observed volume of vehicles. To calibrate and validate the VISSIM, whole dataset is divided into two parts, i.e., traffic on one link is used for calibration and the other link traffic is used for validation. Space-oriented simulation is done due to the fact that neither there is lane marking on the road nor people are seen to obey the rules for driving in lane. Based on the sensitivity analysis, the sensitive parameters of Wiedemann'99 car following model are changed in the base model manually to achieve minimum difference between the actual and simulated flows. Table 2 shows the calibrated values and default values of driver behavior parameters and lane-changing parameters, their notation in the model and description.

\subsection{Statistical analysis; VISSIM}

The observed flow data obtained from videos are compared with the simulated flow of VISSIM. Statistical testing has been done to make the results tangible. GEH statistics is applied on VISSIM results. Table 3 shows the statistical analysis for GEH test. The GEH values for both the directions are well below 5, which suggests that the model is well calibrated and is ready for validation.

Micro-traffic simulation model is then validated using the other set of data (i.e., other direction) from NIPA to Hasan Square. For the same condition of driver behavior, speed distribution, etc., the model was tested, and the simulated results show similarities to real-time observed data as shown in Table 4. Table 4 also shows that validation has been satisfactory based on the results of $\mathrm{GEH}$ statistics. The observed and simulated volume shows little or negligible difference.

To get insight of the traffic condition average delay per vehicle, queue delay time and average speed are also calculated throughout the section. The evaluation is split into two links, one from NIPA to Hasan Square and second from Hasan Square to NIPA. Results obtained are given in Table 5 .

At a such low volume, this section of the road works perfectly fine. There is an average delay of 8.7 and $19 \mathrm{~s}$ on link 1(from NIPA to Hasan Square) and link 2 (From Hasan Square to NIPA), respectively. Results of the model

Table 1 PCSWMM calibration using observed ponding depth

\begin{tabular}{lllll}
\hline No. & Location & Observed depth $(\mathrm{m})$ & Simulated depth $(\mathrm{m})$ & Percent error \\
\hline 1 & E305511.516 & 0.108 & 0.102 & 6.30 \\
& N2755464.517 & & & 0.211 \\
2 & E306036.516 & 0.250 & & 18.59 \\
& N2755819.577 & & 0.112 & 18.12 \\
& E306796.516 & 0.132 & & \\
\hline
\end{tabular}


Table 2 Calibration parameters of car following model Wiedemann'99 in VISSIM

\begin{tabular}{|c|c|c|c|c|c|}
\hline No. & Code & Name & Description $^{\dagger}$ & $\begin{array}{l}\text { Default } \\
\text { value }\end{array}$ & $\begin{array}{l}\text { Used } \\
\text { value }\end{array}$ \\
\hline 1 & $\mathrm{CC} 0$ & Standstill distance $(\mathrm{m})$ & $\begin{array}{l}\text { It is the desired back bumper to front distance between vehicles in the stationary } \\
\text { condition }\end{array}$ & 1.5 & 0.30 \\
\hline 2 & $\mathrm{CC} 1$ & Headway time (s) & $\begin{array}{l}\text { It is the desired time headway in seconds. Summation of both } \mathrm{CC} 0 \text { and } \mathrm{CC} 1 \text { gives the } \\
\text { safety distance at given speed }\end{array}$ & 0.90 & 0.20 \\
\hline 3 & $\mathrm{CC} 2$ & $\begin{array}{l}\text { 'Following' variation } \\
(\mathrm{m})\end{array}$ & $\begin{array}{l}\text { This value plus safety distance gives distance after which the driver intentionally } \\
\text { moves closer to the vehicle in front }\end{array}$ & 4.00 & 4.00 \\
\hline 4 & $\mathrm{CC} 3$ & $\begin{array}{l}\text { Threshold for entering } \\
\text { 'following' }\end{array}$ & It is time in seconds when driver tend to decelerate before reaching to safety distance & -8.00 & -8.00 \\
\hline 5 & $\mathrm{CC} 4$ & $\begin{array}{l}\text { Negative 'following' } \\
\text { threshold }\end{array}$ & $\begin{array}{l}\text { These two values show the sensitivity of driver to react to acceleration (CC5) and } \\
\text { deceleration (CC4) of the vehicle ahead. The smaller the values are, the sensitive }\end{array}$ & -0.35 & -1.25 \\
\hline 6 & CC5 & $\begin{array}{l}\text { Positive 'following' } \\
\text { threshold }\end{array}$ & the reaction is & 0.35 & 1.25 \\
\hline 7 & CC6 & $\begin{array}{l}\text { Speed dependency of } \\
\text { oscillation }\end{array}$ & $\begin{array}{l}\text { It is the stimulus of distance on speed when two vehicles are in 'following process.' } \\
\text { The smaller the value is, the speed oscillation becomes more independent and vice } \\
\text { versa }\end{array}$ & 11.44 & 11.44 \\
\hline 8 & $\mathrm{CC} 7$ & $\begin{array}{l}\text { Oscillation } \\
\quad \text { acceleration }\left(\mathrm{m} / \mathrm{s}^{2}\right)\end{array}$ & It is the acceleration during oscillation process & 0.25 & 0.25 \\
\hline 9 & $\mathrm{CC} 8$ & $\begin{array}{l}\text { Standstill acceleration } \\
\quad\left(\mathrm{m} / \mathrm{s}^{2}\right)\end{array}$ & It is the desired acceleration when a vehicle starts from stationary & 3.50 & 3.50 \\
\hline 10 & CC9 & $\begin{array}{l}\text { Acceleration at } \\
80 \mathrm{~km} / \mathrm{h}\left(\mathrm{m} / \mathrm{s}^{2}\right)\end{array}$ & It is the desired acceleration when a vehicle is traveling at $80 \mathrm{~km} / \mathrm{h}$ & 1.50 & 1.50 \\
\hline 11 & - & $\begin{array}{l}\text { Minimum lateral } \\
\text { distance at } 0 \mathrm{~km} / \mathrm{h}\end{array}$ & $\begin{array}{l}\text { It is the minimum lateral distance in meter between two vehicles when passing each } \\
\text { other in the same lane. These values are provided at } 0 \mathrm{~km} / \mathrm{h} \text {, i.e., standstill and }\end{array}$ & 1.0 & 0.15 \\
\hline 12 & - & $\begin{array}{l}\text { Minimum lateral } \\
\text { distance at } 50 \mathrm{~km} / \mathrm{h}\end{array}$ & $50 \mathrm{~km} / \mathrm{h}$. Actual value is calculated from linear interpolation & 1.0 & 0.20 \\
\hline
\end{tabular}

${ }^{\dagger}$ Taken from VISSIM manual

Table 3 GEH statistics for the calibrated VISSIM model

\begin{tabular}{llccc}
\hline No. & Location of count & Observed volume (veh/h) & Simulated volume (veh/h) & GEH statistics result \\
\hline 1 & At Hasan square, while traveling to NIPA & 1861 & 1863 & 0.046 \\
2 & At NIPA, while traveling from Hasan Square & 877 & 906 & 0.971 \\
\hline
\end{tabular}

Table 4 GEH statistics for validation of VISSIM model

\begin{tabular}{lllll}
\hline No. & Location of count & Observed volume (veh/h) & Simulated volume (veh/h) & GEH statistics result \\
\hline 1 & At Hasan square, while traveling from NIPA & 673 & 611 & 2.45 \\
2 & At NIPA, while traveling to Hasan Square & 640 & 658 & 0.71 \\
\hline
\end{tabular}

Table 5 Results of VISSIM

\begin{tabular}{lllcl}
\hline Link & Location of count & Average spot speed $(\mathrm{km} / \mathrm{h})$ & Average delay per vehicle $(\mathrm{s})$ & Average delay due to queue $(\mathrm{s})$ \\
\hline 1 & From NIPA to Hasan Square & 30.7 & 8.7 & 2.1 \\
2 & From Hasan Square to NIPA & 30.4 & 19.0 & 4.0 \\
\hline
\end{tabular}

show that the speed of the vehicles remains in the range of $30 \mathrm{~km} / \mathrm{h}$. Moreover, the delay due to queue formed is more (4s) on the road from Hasan Square to NIPA, contrary to the other direction which is of 2 s only.

\subsection{Future scenarios}

Future scenarios are based on 50-year and 100-year return period of rainfall. The rainfall values with intensity are 
Table 6 Results of VISSIM for 50-year return period rainfall

\begin{tabular}{|c|c|c|c|c|c|}
\hline Link & Location of count & $\begin{array}{l}\text { Average speed }(\mathrm{km} / \\
\mathrm{h})^{\dagger}\end{array}$ & $\begin{array}{l}\text { Average delay per vehicle } \\
\text { (s) }\end{array}$ & $\begin{array}{l}\text { Average delay due to queue } \\
\text { (s) }\end{array}$ & $\begin{array}{l}\text { Queue length } \\
\text { (m) }\end{array}$ \\
\hline 1 & $\begin{array}{l}\text { From NIPA to Hasan } \\
\text { Square }\end{array}$ & 29.7 & 2098 & 1058 & 1217 \\
\hline 2 & $\begin{array}{l}\text { From Hasan Square to } \\
\text { NIPA }\end{array}$ & 30.0 & 1402 & 1194 & $1143^{\dagger \dagger}$ \\
\hline
\end{tabular}

${ }^{\dagger}$ Average spot speed of those vehicles which have reached to the other end of link

${ }^{\dagger}$ It is the maximum length available in the link for queuing

Table 7 Results of VISSIM for 100-year return period rainfall scenario

\begin{tabular}{llllll}
\hline Link & Location of count & $\begin{array}{l}\text { Average speed }(\mathrm{km} / \\
\mathrm{h})^{\dagger}\end{array}$ & $\begin{array}{l}\text { Average delay per vehicle } \\
(\mathrm{s})\end{array}$ & $\begin{array}{l}\text { Average delay due to queue } \\
(\mathrm{s})\end{array}$ & $\begin{array}{l}\text { Queue length } \\
(\mathrm{m})\end{array}$ \\
\hline 1 & $\begin{array}{l}\text { From NIPA to Hasan } \\
\text { Square }\end{array}$ & 29.8 & 2354 & 916 & $1267^{\dagger \dagger}$ \\
2 & $\begin{array}{l}\text { From Hasan Square to } \\
\text { NIPA }\end{array}$ & 29.7 & 764 & 651 & 660 \\
\hline
\end{tabular}

${ }^{\dagger}$ Average spot speed

${ }^{\dagger}$ It is the maximum length available in the link for queuing

taken from the IDF curve for period of one hour. Furthermore, peak hour traffic is used of the university road [39]. Peak hour traffic is taken from the previous survey. The extrapolated peak hour volume is used as $3040 \mathrm{veh} / \mathrm{h}$ from NIPA to Hasan Square and $2122 \mathrm{veh} / \mathrm{h}$ in the opposite direction. In the survey report, the average daily traffic (ADT) is calculated, which is then converted to peak hour by taking $9.5 \%$ of the ADT [40].

\subsection{0-year return period}

For getting results of ponded area using modeling from PCSWMM, the rainfall intensity and duration are required. By keeping duration of rainfall constant for one hour, and using the IDF curve for Karachi, the resulted intensity is obtained which is $2.6 \mathrm{in} . / \mathrm{h}(66.04 \mathrm{~mm} / \mathrm{h})$. This value is an input to PCSWMM and the program is run. The results show that there is intense ponding at six different locations. On both links, ponding occurred at three locations. On link 1 ponding occurred in front of Urdu University, at U-turn and in front of PIA planetarium. In front of Urdu University, there was ponding over the 40-m stretch, at U-turn ponded length was almost $40 \mathrm{~m}$, and before $100 \mathrm{~m}$ from Baitul Mukarram mosque the ponded length was of $30 \mathrm{~m}$. On link 2 there was ponding after the length of $275 \mathrm{~m}$ from U-turn. The ponded lengths are 40 and $140 \mathrm{~m}$ having a bare road surface of around $25 \mathrm{~m}$ in between.

In ponded areas drivers tend to drive more slowly; therefore, two other speed distributions are made based on the physical observation. Speed distributions are made, keeping the depth of ponding. The higher the ponding depth is, the less the vehicle speed is. For VISSIM, the minimum speed of vehicles is kept as $5 \mathrm{~km} / \mathrm{h}$. Also, $75 \%$ vehicles have speed between 5 and $20 \mathrm{~km} / \mathrm{h}$, and the rest $25 \%$ of the vehicles have speed between 20 and $30 \mathrm{~km} / \mathrm{h}$. Speed values are taken very carefully after examining the behavior of drivers crossing less ponded (0-4 in depth) areas. Similarly, $50 \%$ vehicles have speeds between 0 and $10 \mathrm{~km} / \mathrm{h}$, while the rest $50 \%$ have speeds between 10 and $20 \mathrm{~km} / \mathrm{h}$ at ponded depth more than $4 \mathrm{in}$. All of these numbers are based on the observations made on site.

As VISSIM provides results for the delay, travel time, and number of vehicles in queue, the simulated results for 50 -year return period of rainfall and peak hour traffic for the study section are given in Table 6 . The results are the average of 5 runs to minimize the variability.

Table 6 illustrates that for a 50-year return period the maximum delay will become $2098 \mathrm{~s}$ ( $\sim 35 \mathrm{~min}$ ) in the direction from NIPA to Hasan Square, which is higher as compared to the delay on the other direction that is $1402 \mathrm{~s}$ ( $23 \mathrm{~min}$ ). From Hasan Square to NIPA, the average delay due to queue is $1194 \mathrm{~s}$ which is higher than the parameter value of the other direction. Speed predicted for the 50-year return period shows that on both directions, it has not changed from the existing scenario.

\subsection{0-year return period rainfall}

The only variable that needs to be changed compared to the previous run is the amount of rainfall. For a 100-year return period, the amount of rainfall is coming out to be $81 \mathrm{~mm}$ (3.2 in.). After applying this value to the nodes, model is 
run for the 100-year return period rainfall. On link 1, another pond of around $30 \mathrm{~m}$ is introduced into the study area, which is located just after the point where vehicles take right turn (U-turn). Other ponded areas, discussed in previous scenario, are the same with the approximate increase in a length of $10 \mathrm{~m}$. This increase in length was anticipated, because now during a 100-year return period more water tends to accumulate. Rest of the results are very much similar to the 50-year return period analysis.

Data in this section also remain the same as discussed for previous scenario, except that a new ponded area is defined, which is ponded in this case only. Reduced speed areas are defined. Similar results are shown for VISSIM model as for previous scenario. Table shows the analysis for 100-year return period, and again results are the average of 5 runs of the same model to minimize the effect of extreme values.

In Table 7, the results from VISSIM show that maximum delay per vehicle is $2354 \mathrm{~s}(\sim 39 \mathrm{~min})$ and average queue delay is $916 \mathrm{~s}$ ( $\sim 15 \mathrm{~min})$, having queue length of $1267 \mathrm{~m}$ in the direction from NIPA to Hasan Square, while in the opposite direction, the maximum delay is $764 \mathrm{~s}$ $(\sim 13 \mathrm{~min})$.

\section{Conclusions and recommendations}

It has been concluded that despite ponding, for lesser volume, both links under study have no or small delays in traffic; however, for high volumes, the delay of 8.7 and $19 \mathrm{~min}$ is observed from NIPA to Hasan Square and vice versa, respectively. The second link (Hasan Square to NIPA) has more delay due to congestion caused by the right turning. Sensitivity analysis shows that standstill distance ( $\mathrm{CC} 0$ ), time headway ( $\mathrm{CC} 1)$, and lateral distance between vehicles at 0 and $50 \mathrm{~km} / \mathrm{h}$ are the most sensitive parameters of VISSIM. Results from PCSWMM also concludes that for the 50-year and 100-year return periods of rainfall, there would be 0.318 and 0.328 ha-m of inundation, on link 1 and link 2, respectively, even after $10 \mathrm{~h}$ of the event. The delay due to this ponding can be up to $39 \mathrm{~min}$ for the 100 -year return period scenario. This is because of few outlets and/or no drainage system for ponded water. From this study, it can be concluded that the loose coupling of both models, PCSWMM and VISSIM, if calibrated and validated accordingly, is effective in terms of incorporating and then evaluation of the effect of hydrologic conditions for various traffic scenarios.

Open Access This article is distributed under the terms of the Creative Commons Attribution 4.0 International License (http:// creativecommons.org/licenses/by/4.0/), which permits unrestricted use, distribution, and reproduction in any medium, provided you give appropriate credit to the original author(s) and the source, provide a link to the Creative Commons license, and indicate if changes were made.

\section{References}

1. Matin F, Herani GM, Warraich UA (2012) Factors affecting traffic Jam in Karachi and its impacts on performance of economy. KASBIT Bus J 5:25-32

2. Matagi SV (2002) Some issues of environmental concern in Kampala, the Capital City of Uganda. Environ Monit Assess 77(2):121-138

3. Tucci CEM (2001) Some scientific challenges in the development of South America's water resources. Hydrol Sci J 46(6):937-946

4. Salma S, Shah MA, Rehman S (2012) Rainfall trends in different climate zones of Pakistan. Pak J Meteorol 9(17)

5. USEPA (2013) Climate change indicators in United States: US and global precipitation. US

6. Maqsood H, Ahmed SI, Ahmed S (2013) Assessment of weather indicators for possible climate change. In: Environmentally sustainable development (ESDev). Abbottabad, Pakistan

7. Agarwal M, Maze TH, Souleyrette R (2005) Impacts of weather on urban freeway traffic flow characteristics and facility capacity. In: Mid-continent transportation research symposium, Iowa

8. Smith BL et al (2004) An Investigation into the impact of rainfall of freeway traffic flow. In: 83rd Annual meeting of the Transportation Research Board, Washington, DC

9. Bartlett AP et al (2013) Impact of inclement weather on hourly traffic volumes in Buffalo, New York. In: 92nd Meeting of Transportation Research Board, Washington, DC

10. Feng $\mathrm{H}$ et al (2011) Modeling the impacts of related factors on traffic operation. Procedia Eng 12:99-104

11. Kyte $M$ et al (2002) Effect of weather on free-flow speed. Transportation Research Board, pp 60-68

12. Chung Y (2012) Assessment of non-recurrent congestion caused by precipitation using achived weather and traffic flow data. Transp Policy 2012(19):167-173

13. Sterzin ED (2004) Modelling influencing factors in a microscopic traffic simulator. In: Department of Civil and Environmental Engineering Massachusetts Institute of Technology, Massachusetts, p 95

14. Cools M, Moons E, Wets G (2010) Assessing the impact of weather on traffic intensity. Am Meteorol Soc 2:60-68

15. HEC-RAS (2006) River analysis system, user's manual. Version 4.0 Beta ed, ed. U.A.C.o. Engineers. Hydrologic Engineering Center

16. Bicknell BR et al (2001) Hydrological simulation programFortran (HSPF), User's manual. 12 edn. Reston, VA: U.S. EPA National Exposure Research Laboratory, Athens, GA, in cooperation with U.S. Geological Survey, Water Resource Division

17. P.T.V. VISSIM (1992) PTV Planung Transport Verkehr AG, Germany

18. CORSIM, McTrans Centre, Traffic micro-simulation software (1998) Albany, Florida, U.S.: University of Florida. Traffic Micro-Simulation software

19. Simtraffic, Trafficware corporation, Traffic micro-simulation software (1990) Barcelona, Spain. Traffic Micro-simulation software

20. AIMSUN Traffic Simulation System (TSS), Traffic Micro-simulation Software. Barcelona, Spain

21. PARAMICS (1974) Quadstone Paramics, Traffic micro-simulation software, UK

22. Mark O et al (2004) Potential and Limitation of 1D modelling of urban flooding. J Hydrol 299:284-299 
23. Chen J, Hill AA, Urbano LD (2009) A GIS-based model for urban flood inundation. J Hydrol 373(1-2):184-192

24. Hsu MH, Chen SH, Chang TJ (2000) Inundation simulation for urban drainage basin with storm sewer system. J Hydrol 234(1-2):21-37

25. Shrestha A, Chaosakul T, Priyankara DPMP, Chuyen LH, Myat SS, Syne NK, Irvine KN, Koottatep T, Babel MS (2014) Application of PCSWMM to explore possible climate change impacts on surface flooding in a Peri-urban area of Pathumthani, Thailand. J Water Manag Model. ISSN 2292-6062

26. Schmitt TG, Thomas M, Ettrick N (2004) Analysis and modelling of flooding in urban drainage systems. J Hydrol 299:300-311

27. Hou $\mathrm{T}$ et al (2013) Calibration of traffic flow models under adverse weather and application in mesoscopic network simulation procedures. In: 92nd Annual meeting of Transportation Research Board. Washington, DC

28. Asamer J, Van Zuylen HJ, Heilmann B (2011) Calibrating VISSIM to adverse weather conditions. In: 2nd International conference on models and technologies for intelligent transportation systems, Leuven, Belgium

29. Gomes G, May A, Horowitz R (2004) A microsimulation model of a congested freeway using VISSIM. In TRB annual meeting, Traffic Research Board, Washington, DC

30. Bloomberg L, Jame D (2000) Comparison of VISSIM and CORSIM traffic simulation models on a congested network. J Transp Res Board 1727:52-60

31. Barceló J (2010) Fundamentals of traffic simulation. International Series in Operations Research \& Management Sciences, vol 145. Springer, New York
32. Jones SL et al (2004) Traffic simulation software comparison study. Department of Civil \& Environmental Engineering, The University of Alabama at Birmingham, Birmingham

33. International, C.H.I., PCSWMM (1998) Computational hydraulics international: Guelph, Ontario, Canada. PCSWMM GIS Software

34. Rossman LA (2010) Storm water management model user's manual, version 5.0. National Risk Management Research Laboratory, Office of Research and Development, US Environmental Protection Agency

35. Planing Tranpsport Verkehr (PTV), A., VISSIM-user manual. 5.40 ed. 2012, Germany: PTV Vision. 763

36. TRB, Highway Capacity Manual (HCM) (2010) Washington, DC: Traffic Research Board of the National Academics, National Research Council

37. DMRB (2013) Design manual for roads and bridges, vol 12. UK, p 149

38. Olstam JJ, Tapani A (2004) Comparison of car following models. Swedish National Road and Transport Research Institute, Sweden, $\mathrm{p} 45$

39. Afroz $\mathrm{S}$ et al (2008) Traffic analysis of corridor connecting NIPA, Abul Hasan Isphani road, and Johar road and geometric design of double T-intersection at Samama shopping centre, on University road, in urban \& infrastructure engineering 2008, NED University of Engineering \& Technology, Karachi, p 54

40. Bassan S (2013) Modelling of peak hour factor on highways and arterials. KSCE J Civ Eng 17(1):224-232 